\title{
The Household Registration System of Problem Analysis and Suggestions about Chengdu
}

\author{
Yin FANG ${ }^{1, a,{ }^{*} \text {, Chang GOU }}{ }^{2, b}$, Yu-Kun GUO ${ }^{3, c}$, Hui LIU ${ }^{4, d}$ \\ ${ }^{1}$ Institute of Management, Southwest University for Nationalities, Chengdu, Sichuan, China \\ ${ }^{2}$ Institute of Management, Southwest University for Nationalities, Chengdu, Sichuan, China \\ ${ }^{3}$ Institute of Management, Southwest University for Nationalities, Chengdu, Sichuan, China \\ ${ }^{4}$ Institute of Management, Southwest University for Nationalities, Chengdu, Sichuan, China \\ a362467183@qq.com, b101492899@qq.com, 77528934@qq.com, d34103564@qq.com. \\ ${ }^{*}$ Corresponding author
}

Keywords: Chengdu, Reform of census register system, Integration of urban, Rural household unified.

\begin{abstract}
By Chengdu's household registration system reform background and main contents of research, found that the existence of economic development power and the contradiction between the capital, the reform of farmers living, quality problems to the household registration system reform under the urban and rural integration challenge problems, puts forward the promoting economic development, to provide a solid material foundation for reform; To speed up the legislative process, improve the supporting legal policy system; Cultivating citizen culture, further enhance farmers' quality, etc. Counter measures and Suggestions. Not only help to better promote the reform of Chengdu, the household registration system, but also to the current household registration system reform in China is of great significance.
\end{abstract}

\section{Introduction}

In November 2010, Chengdu government issued" Advices concerning adjustment of current household registration system to realize the freedom of movement", which aims to make the household registration back to its basic function of register replaced for the attached privilege to it. In addition, "residence card" was carried out to give floating people similar rights and security with local citizens. Moreover, increasing fund were input to the education, healthcare and social security to develop the equity of public service. The reform of "united household registration system" is described as the most thorough reform of household registration in China until now, which causes high concern from the community [1]. Under the circumstance of much doubtful about domestic current household registration system and of much pressure on the reform, Chengdu's experience has a significant meaning.

\section{The background of reform of household registration system of Chengdu}

Chengdu became the test zone of overall urban-rural plan in June 2007 since when Chengdu government has made a series of reforms from the rural land system to some other areas concerning education, medical security and social security to realize the equality in public service and welfare between urban and rural residents. Not only has these reforms weaken the privilege attached to household registration, but also laid the foundation of reform of household registration system. Rural Property system is a main factor affecting the movement of rural residents into the city. The Reform of property system of Chengdu started from 2008 derived the affirming rights to rural land. Homestead right to use property and land-use contract management have been fixed as property rights to farmers with certificates to make it clearer given by village collectives. At the same time, Chengdu government has set up rural property exchanges in which farmers can transfer their land-use contracts in order to make it into liquid assets. It makes the lands become transferable production factors, which ensures the farmers' benefits when they move into cities and release the burden of lands and houses on their shoulders[2]. 
The gap between urban and rural public service makes the reform of household registration system harder. The superior public service is one of the forces encouraging rural residents rush into cities. Therefore Chengdu has invested 1.45 billion, which be used to build 410 Standardized schools, improve the salaries of rural teachers and make the elite schools collectivization to drive the near and distant suburban schools developing. 760millions has been invested to complete the construction of rural health centers and posts to improve the level of primary medical and health care. More investment has been put into Social security which coverage also been broaden. In 2004, Chengdu government included the land-lost peasants into urban endowment and medical insurance in the way of financial subsidy. At the same time, Chengdu takes the initiative to merge the new rural cooperative medical care system (NCMS), urban residents' basic medical insurance (URBMI) and municipal college students' health insurance as an Urban and rural residents medical treatment insurance. According to the contrast data provided by Chengdu government, the gap of input of per capita public service between urban and countryside is 1,542yuan in 2004 and the number descended to 136.2yuan in 2009 [3].

These series of reforms has shortened the gap of rights attached to household registration between urban and rural residents balanced the public service offering and laid the foundation of reform of household registration system.

\section{Content of the reform of household registration system of Chengdu}

Chengdu started to adjust the household registration system from the year of 2003. On the basis of the documents issued by local authorities----" Advices concerning adjustment of current household registration system", in which" indicator of settling in city" was instead by the condition "legal fixed residence, stable job or source of income" as the criteria of settling in the city.

In 2004, Chengdu government braking the binary policy in urban and rural household registration system and unifying the past" agricultural" and" non-agricultural" type of household registration into "resident household"

After the year of 2006, the access condition was further broaden by authorities .All the rural residents who have rent or bought houses in Chengdu can be permitted to register urban household [4]. In November 2010, Chengdu issued "Advices about unifying urban and rural household registration to realize the freedom of movement". Its content was mainly about the flowing points: establish a united household registration system; unify employment and unemployment registration and complete employment assistance system; complete the united urban and rural social insurance system; unify discharged soldiers subsidy system; unify urban and rural housing guarantee system grouping by districts; realize the equality of compulsory education; establish an united urban and rural birth control system. Above all, Chengdu dedicated to promoting civil rights and democratic rights between both urban and rural residents. It has become the model of domestic reform of household registration system. The united urban and rural household registration also promoted the balance of public resources and rational population distribution. Chengdu put residence card policy into practice in January 2011. According to the file issued in July 2010 ,people living in Chengdu over one year who are working or owning or renting house in the city can apply for residence card if they have paid social insurance fee over 6 months. Once these people own the card, they have equal rights with local citizens in employment, Medicare service, birth control, legal aid, etc. This reform changed the used restriction that rights depend on residence registration. Not only local rural residence but also floating people can enjoy the similar social insurance with the local citizens[5].

\section{Problems in the reform of household registration system of Chengdu}

\section{Contradictions between economy and reforming fund}

Lacking of reforming funds to support the reform is the most outstanding problem for Chengdu government. The financial pressure derives mainly from two aspects: (1) Lack of fund sources. Although In 2010, municipal budgeted revenue got to the number of 52.69 bilillon, increased by $30.1 \%$ compared to 2009 [6], it has not meet the need of reform. Rural residents in Chengdu are not rich enough to afford 
the cost of reform. (2) Lack of enough fund inputted into the reform. It is essential to input a large amount of reforming funds to complete the reform, in contrast to it, the lack of fiscal revenue make things difficult. Such as farmland-protection fund of Chengdu, usually unstable for affecting by the situation of land market, it is mainly from land transfer funds. Though there is 6.6 million mu farmland in Chengdu, only 5 million farmland-protection fund has been offered by district(city)counties until now [7]. With the process of this reform, much more fund are needed. Lacking sufficient reforming fund has brought many projects a halt for Chengdu. It is essential to get strong support from public finance either for establishing equal public services or a rural social security system.

\section{Rural residential problem challenge the reform}

It is the main problem for the reform to be solved out in countries. Chengdu has built up 8 million square meter new rural communities with 21000 rural resident living there [8]. It is good to utilize rural construction land intensively, transfer land and scale up agriculture production for Centralism housing for rural resident. But some disadvantages still exist such as it is too far from the living house to the contracted land to put away the farm instruments. On the other hand, it makes it difficult to feed livestock to shark the farmers' income. Furthermore, the farmers have to pay a part of moving cost in contrast with the difficult of get enough income from land transferring to meet the need.

\section{The personal problems of rural residents}

Because of the personal low level of education, domestic farmers are used to traditional agriculture production experience and resist initiative reforms including marketing economy, advanced scientific and technological information, modern production methods and management experience, etc. Only do the farmers' conception changed, can they adjust to the current reform and accelerate the process of reform.

\section{Advices}

\section{Develop the economy in order to ensure solid material foundation}

According to the sixth nationwide population census, the population of Chengdu has get to 14.04million and until the end of 2010 the urbanization rate increased to $65.1 \%$.It also means there are still 5.04million rural residents in Chengdu [9]. If these people are incorporated into the same social security system as citizens', it is critical to have a solid material foundation. Once the development of economy cannot meet the demand of social reform, the reform would switch into census register reform. And it may stop at the established united urban and rural household register system more than changing relevant economic social relation. Therefore government should accelerate economic growth to increase fiscal revenue and broaden the sources of reforming fund. Considering the geographic location(inland) and the development of economy, Chengdu should develop strategies that construct inland opening economy system. Accelerate constructing modern industrial system, developing service industry, promoting pillar industry, fostering rising service industry. Followed by economic development, promote the innovation of rural financial products and services, explore modern agriculture insurance system and strengthen the financial support to the "agriculture, rural areas and farmers".

\section{Improve legal and policy system}

The reform of balanced development of urban and rural areas and of household registration should carry out in the regulation of constitution. Rights should not be attached to the urban or rural character. In the process of making laws, neither should repeat the past inequity to the rural areas and farmers nor do in the name of "compensate" to make up for the inequity, which is the basic requirement of modern democratic politics [10] .In general, implement new laws conform to the constitutional principal while abolishing the legislation that against the spirit of freedom of movement. Specifically, new household registration law should be laid down to return the Enrollment functions of household register to it. The right of use of homestead, land contract, social welfare, social security concerned in the reform should be regulated and adjusted in the legislation such as property law or contract law or social security law or education law, etc. Not only should legal protection but also functional departments should cooperate 
with it. For example ,panning department take responsible of planning the public facilities concerning healthcare station, school, shopping mall and so on of new communities. Some measures about distributing education resources and carry out the policy of urban and rural areas share the superior education should be given to the education department. Moreover, civil affairs department is responsible for policies about employment and social security or insurance. Agriculture department should issue new policy about agriculture industrialization. Control birth department should adjust the regulation to the new situation.

\section{Foster the modern farmers with citizen culture}

For getting the target of "large Chengdu", government should explore diversities of ways to complete regulations of rural residents settle down in the city and of citizens back to live in rural areas. Ensure the equity of education, healthcare, social security, housing between migrant farmers and citizens. In addition, it is essential to improve rural residents' personal quality in ways of organizing skill training, entertainment activities ,etc. Encourage traditional farmers switch into citizens to adjust to the modern lifestyle.

\section{Acknowledgements}

This research was financially supported from the key programs of the Postgraduate Innovation by Southwest University for Nationalities. (No. CX2014SZ03)

\section{Literature References}

[1] Cui Qing-wu. Reflections on the reform of the household registration system in Chengdu mode [J]. Population and economic,2012(2).

[2] Gao Zhu. Focus Chengdu household registration reform: China's household registration system, the most radical reform program [N]. Worker's Daily,2010.

[3] CASS Institute of Urban Development and Environment: 《China Urban Development Report (2010)》 [J]. Social Sciences Academic Press,2010.

[4] Lu Yi-long. Justice: A Sociological Perspective of Chinese household registration system [J]. Hunan Social Sciences,2004,(1).

[5] Ma Fu-yun. The plight of China's household registration system reform and its solution [N]. Beijing University of Technology Journal ,2011(9),27(3).

[6] Gou Yin-ping,Cao Hai-hua,Zhu Jing-song. Change and thinking in the early years of New China, urban-rural relations [J]. Business Times,2010(26).

[7] Niu Xiong. Population policy research to build the main functional areas [J]. Reform Strategy,2009(4).

[8] Cai Fang. Household registration system reform and social welfare and rural co-ordinate system [J]. Economics News,2010(12).

[9] Pang Li-hua. Chinese household registration system reform: Problems and Solutions [J]. Population and Development,2009(6).

[10] Gai Hong-wei、Zhang Yi-zhe:Research on the reform of the household registration system under the abolition dilemma [J]. Hebei University Journal(Philosophy and Social Sciences),2011. 